\title{
Supporting Information for Optimizing Structural and Mechanical Properties of Coiled Carbon Nanotubes with NSGA-II and Reactive Molecular Dynamics Simulation
}

Ehsan Shahini ${ }^{\text {a,* }}$, Fazel Rangriz ${ }^{\text {b }}$, Ali Karimi Taheri ${ }^{\text {, }}$, Mojtaba Abdi-Jalebi d,*

${ }^{a}$ Department of Mechanical Engineering, University of Alberta, Edmonton, Alberta, Canada.

b Department of Electronic Systems, Norwegian University of Science and Technology, NTNU, NO-7491 Trondheim, Norway.

c Department of Material Science and Engineering, Sharif University of Technology, Azadi Ave., Tehran, Iran.

d Institute for Materials Discovery, University College London, Malet Place, London, WC1E 7JE United Kingdom.

Emails: shahini@ualberta.ca, Tel: +1 5879382114, m.jalebi@ucl.ac.uk, Tel: +44 (0)1223 336066

Table S1. A summary of the results of experimental and computational research on the uniaxial tension of CCNTs.

\begin{tabular}{|c|c|c|c|c|c|c|c|c|}
\hline Reference & $\begin{array}{l}\text { Tube } \\
\text { diameter } \\
(\AA)\end{array}$ & $\begin{array}{l}\text { Pitch } \\
\text { length } \\
(\AA)\end{array}$ & $\begin{array}{l}\text { Coil } \\
\text { radius } \\
(\AA)\end{array}$ & $\begin{array}{l}\text { Elastic } \\
\text { modulus } \\
(\mathrm{GPa})\end{array}$ & $\begin{array}{l}\text { Yield } \\
\text { strain }\end{array}$ & $\begin{array}{l}\text { Yield } \\
\text { stress } \\
(\mathrm{GPa})\end{array}$ & $\begin{array}{l}\text { Fracture } \\
\text { strain }\end{array}$ & $\begin{array}{l}\text { Method } \\
\text { /Material }\end{array}$ \\
\hline 1 & 400 & 1200 & 2000 & 170 & - & - & - & $\begin{array}{l}\text { Experimental/ } \\
\text { CCNT }\end{array}$ \\
\hline 2 & 600 & 1200 & 945 & 0.005 & - & - & 0.42 & $\begin{array}{l}\text { Experimental/ } \\
\text { CCNT }\end{array}$ \\
\hline 3 & - & 1000 & 720 & 100 & & & 2.00 & $\begin{array}{l}\text { Experimental/ } \\
\text { CCNT }\end{array}$ \\
\hline 4 & 300 & 100 & 700 & 0.001 & - & - & 2.30 & $\begin{array}{l}\text { Experimental/ } \\
\text { CCNT }\end{array}$ \\
\hline 5 & 230000 & 300000 & 225000 & 0.0002 & 0.25 & 0.07 & 2.85 & $\begin{array}{l}\text { Experimental } \\
\text { /Carbon } \\
\text { Nanotube } \\
\text { Ropes }\end{array}$ \\
\hline
\end{tabular}




\begin{tabular}{|c|c|c|c|c|c|c|c|c|}
\hline 6 & 1250 & 4500 & 2700 & 5.5 & - & - & - & $\begin{array}{l}\text { Experimental } \\
\text { /CCNT }\end{array}$ \\
\hline 7 & - & 4900 & 300 & 0.05 & 2.0 & 0.1 & 2.08 & $\begin{array}{l}\text { Experimental } \\
/ \mathrm{CCNT}\end{array}$ \\
\hline 8 & 133 & 328 & 97.5 & 9.3 & - & - & - & $\begin{array}{l}\text { Experimental } \\
\text { /Multi-walled } \\
\text { CCNT }\end{array}$ \\
\hline 9 & 4.0 & 24 & 7.5 & 286 & 0.25 & 70.6 & 0.5 & $\begin{array}{l}\text { MD- } \\
\text { FEM/CCNT }\end{array}$ \\
\hline 10 & 6.78 & 167.6 & 81.5 & 17.12 & 0.38 & 6.5 & 1.97 & $\mathrm{MD} / \mathrm{CCNT}$ \\
\hline 11 & 8.17 & 11.9 & 14.63 & 10.22 & 2.31 & 23.61 & 7.2 & $\mathrm{MD} / \mathrm{CCNT}$ \\
\hline 12 & 5.54 & 11.15 & 7.37 & 9.62 & 0.85 & 8.10 & 3.1 & $\mathrm{MD} / \mathrm{CCNT}$ \\
\hline 13 & 11.57 & 14.53 & 13.35 & 0.54 & 2.30 & 1.25 & 5.9 & $\mathrm{MD} / \mathrm{CCNT}$ \\
\hline 14 & 17.73 & 25.17 & 25.57 & 2.47 & 1.61 & 3.98 & 7.30 & $\mathrm{MD} / \mathrm{CCNT}$ \\
\hline 15 & 8.0 & 15.0 & 10.0 & 56.25 & 0.16 & 9.00 & 0.36 & $\mathrm{MD} / \mathrm{CCNT}$ \\
\hline
\end{tabular}

\section{Structural modeling of CCNTs}

Four major steps were carried out to generate a CCNT:

1. It is widely known that imposing non-hexagonal carbon rings into a graphene sheet introduces Gaussian curvature 16,17. For the first step, the desired polygon Toroidal Carbon Nanotube (TCNT), which can be seen in Figure S1b, was obtained from a planar graphene sheet as shown in Figure S1a through a cut-and-fold procedure. The widths and heights of the 
$\mathrm{BCC}^{\prime} \mathrm{B}^{\prime}$ and $\mathrm{ADD}^{\prime} \mathrm{A}^{\prime}$ rectangles supply four degrees of freedom to define any possible TCNT. The four indices from Figure $\mathrm{S} 1\left(\mathrm{n}_{75}, \mathrm{n}_{77}, \mathrm{n}_{55}, \mathrm{~s}\right)$ are defined as follows:

$\mathrm{n}_{75}=$ topological distance between inner-ring heptagons and outer-ring pentagons

$\mathrm{n}_{77}=$ topological distance between inner-ring heptagons

$\mathrm{n}_{55}=$ topological distance between adjacent heptagons and pentagons along the vertical direction

$\mathrm{s}=$ length of the unit cell

2. In the next step, with either inner-rim or outer-rim horizontal shifting (HS), or even a combination of both, distorted TCNTs were created. A 30-degree rotation (HS=1) for the central hollowed hexagonal hole is defined by moving heptagons or pentagons to suitable coordinates on the graphene honeycomb lattice as shown in Figure S1c. With carefully chosen parities of the four indices and the size of horizontal shifting described above, one can obtain TCNTs with $\mathrm{D}_{\text {nd }}$ or $\mathrm{D}_{\text {nh }}$ symmetries as shown in Figure $\mathrm{S} 1 \mathrm{~d}, \mathrm{e}^{18}$.

3. It should be noted that the achieved TCNTs by step 2 possess high strain energy. By dissecting the TCNT along any of its longitudes, the strain energy is released and a CCNT is generated. The more distorted the initial parent TCNT is, the more helicity the CCNT obtained ${ }^{18}$. The relation between pitch angle and the HS is expressed as ${ }^{19}$ :

$$
\theta=\arctan \left(\frac{H S}{g}\right) ; \text { for } H S<10
$$

Where $\theta$ is the pitch angle, and $g$ is the circumference or girth of the TCNT. Moreover, the number of atoms in the CCNT is given by

$$
N=2 n_{77 . s}+2 n_{75}\left(2 s+n_{75}\right)+2 n_{55}\left(n_{75}+s\right)
$$

4. The geometry optimization was carried out by molecular mechanics method with pairwise potential proposed by Lenosky et al. ${ }^{20}$ to make the bond length and the bond angles close to $1.43 \AA$ and 120 degrees, respectively. 
(a)

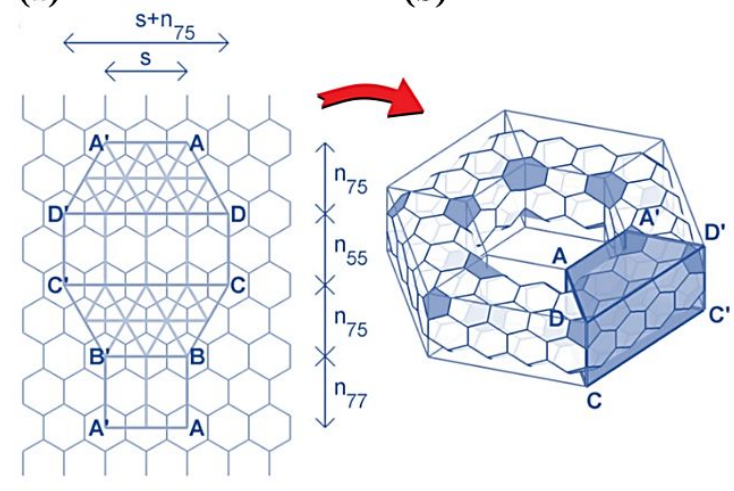

(c)

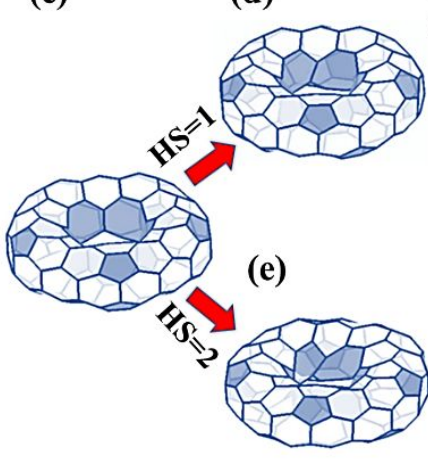

(f)

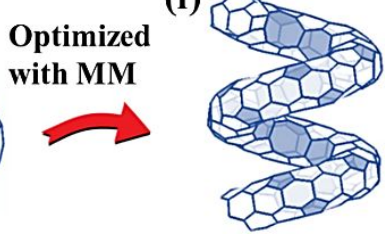

(g)
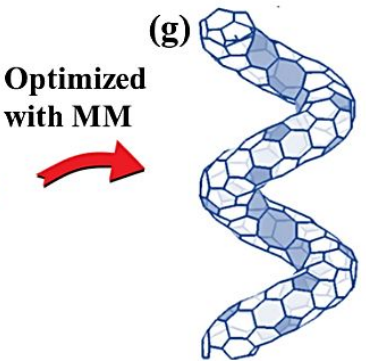

Figure S1. The formation of a CCNT from its parent TCNT. (a) a planar graphene sheet for the cut and fold process. (b) A typical $\mathrm{D}_{6 \mathrm{~d}}$ TCNT with indices $(\mathrm{n} 75, \mathrm{n} 77, \mathrm{n} 55, \mathrm{~s})=(2,1,1,2)$. The shaded region shown is a particular rotational unit cell. (c) A typical parent $\mathrm{D}_{5 \mathrm{~h}}$ TCNT. (d) TCNT after an HS operation. The HS of this TCNT is unity. (e) with HS = 2. (f) CCNT derived from HS-TCNT in part (d). CCNT obtained by dissecting the HS-TCNT shown in previous parts at any of its longitudes. (g) CCNT derived from the HS-TCNT in part (e).

Therefore, six indices suffice to determine a typical CCNT; the first four indices correspond to the parent TCNT, the fifth index is either 1 for $\mathrm{D}_{\text {nd }}$ symmetry or 2 for $\mathrm{D}_{\text {nh }}$ symmetry, and the last index specifies the HS parameter. By changing these six indices, all possible CCNTs with different coil diameter, tube diameter, pitch angle, and pitch length can be modeled. it is noteworthy that not every combination of these six indices yields a stable structure. As a consequence, the structures were examined to verify if they were thermodynamically stable before the tension. In the following, we do not strictly distinguish CCNT, Helical CNT, nanocoil, and nanospring, hence they will be used interchangeably.

It should be noted that all structures in this study are generated from a perfect unit cell i.e. they perfectly connect with the next segment. A typical CCNT with indices $(3,3,4,2,1,2)$ with one, two, and three unit cells that are generated with our code is shown in Figure S2. 


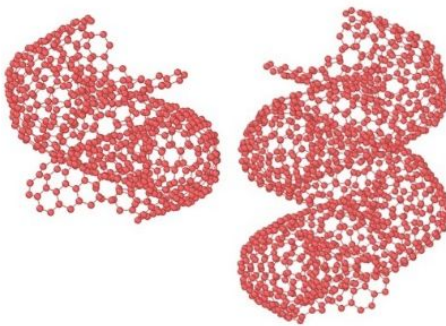

Number of unit cells: 1
2

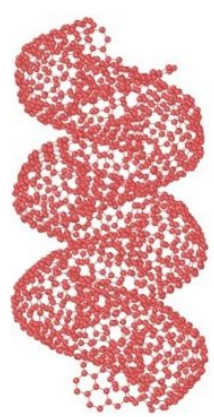

3

Figure S2. A typical CCNT with indices $(3,3,4,2,1,2)$ with three different number of unit cell. Multi-objective process optimization, Pareto front, and NSGA-II

A multi-objective optimization problem is an optimization problem that involves multiple objective functions ${ }^{21}$. For the present work, it can be mathematically formulated as

$$
\operatorname{Max} f\left(a_{i}\right)=\left(f_{1}\left(a_{i}\right), f_{2}\left(a_{i}\right)\right)^{\prime}
$$

$$
\text { s.t. } a_{i} \in A, i \in\{1,2, \ldots, 6\}
$$

Where $f_{1}$ and $f_{2}$ are the objective or fitness functions which can be yield strength or yield strain, $a_{1}, \ldots, a_{6}$ are the six indices needed to identify a CCNT and the set $A$ is the feasible set of decision vectors that will be defined regarding the nanotube size (see section 3). In bi-objective optimization, there does not typically exist a feasible solution that minimizes both objective functions simultaneously ${ }^{22}$. Consequently, attention is paid to Pareto optimal solutions. That is to say, solutions that cannot be improved in any of the objectives without degrading another objective ${ }^{22}$. In mathematical terms, a feasible solution $a^{1} \in A$ is said to (Pareto) dominate another solution $a^{2} \in A$, if ${ }^{23}$

$$
\begin{gathered}
f_{i}\left(a^{1}\right) \leq f_{i}\left(a^{2}\right) \forall i \in\{1,2\} \text { and, } \\
f_{j}\left(a^{1}\right) \leq f_{j}\left(a^{2}\right) \exists j \in\{1,2\}
\end{gathered}
$$


A solution $a^{*} \in A$ (and the corresponding outcome $f_{i}\left(a^{*}\right)$ ) is called Pareto optimal if there does not exist another solution that dominates it. The set of Pareto optimal outcomes is often called the Pareto front or solutions with the first rank ${ }^{22}$. If the solutions related to the current Pareto front are eliminated from the set $A$, the new Pareto front is considered to be the solutions with the second rank. The same procedure can be used to determine other ranks. (Figure S3)

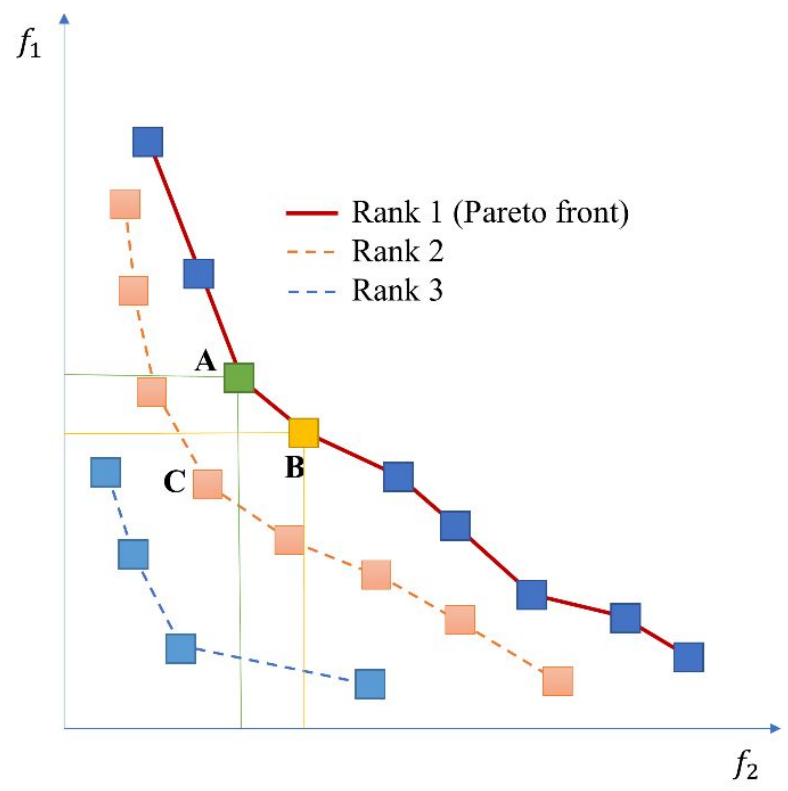

Figure S3. Example of a Pareto front (in red). The boxed points represent feasible solutions, and larger values are preferred to smaller ones. Point $\mathrm{C}$ is not on the Pareto front because it is dominated by both point A and point B. Points A and B are not strictly dominated by any other, and hence do lie on the Pareto front. The solutions with ranks 2 and 3 are drawn with orange and blue dots, respectively. 

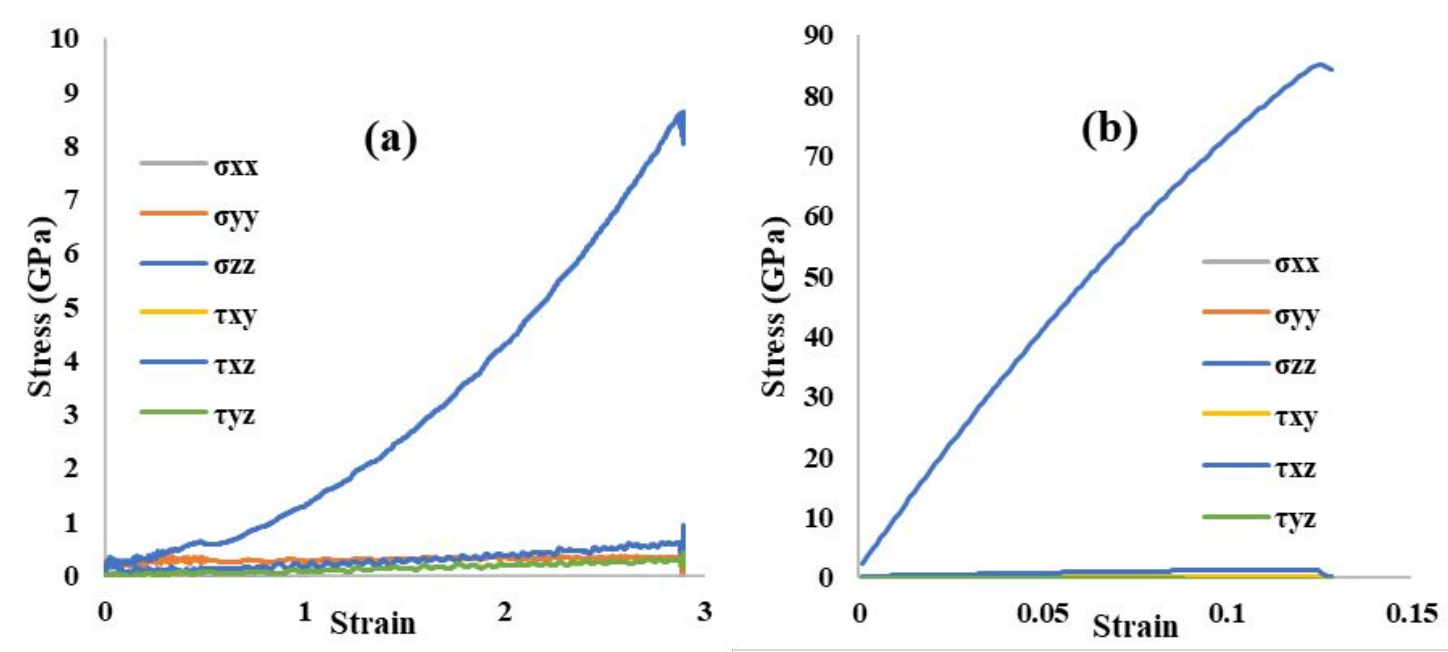

Figure S4. Variations of six stress components in stress-strain curves for (a) CCNT with the pitch angle $=10$ degrees and (b) pitch angle $=85$ degrees. The domination of $\sigma_{z z}$ in stress tensor for the uniaxial test of helical CNTs is obvious.

\section{Effect of strain rate}

MD simulation studies are performed using very high stresses (strain rates), which are only directly comparable to those applied during shock loading experiments ${ }^{24}$. The main reason that high strain rates are used in MD simulations is due to limited computational resources. It is found in the literature that the strain rates in the tensile test should be held under $10^{9} \mathrm{~s}^{-1}$ to get reasonable structure responses and stress values ${ }^{25,26}$. Fortunately, the elastic region is not intensively affected by the strain rate. To show this, two tensile tests for a CCNT were performed with two strain rates of $10^{7} \mathrm{~s}^{-1}$ and $10^{9} \mathrm{~s}^{-1}$. Results are shown in Figure S5. It can be seen that both results display the same value for yield stress and strain. 


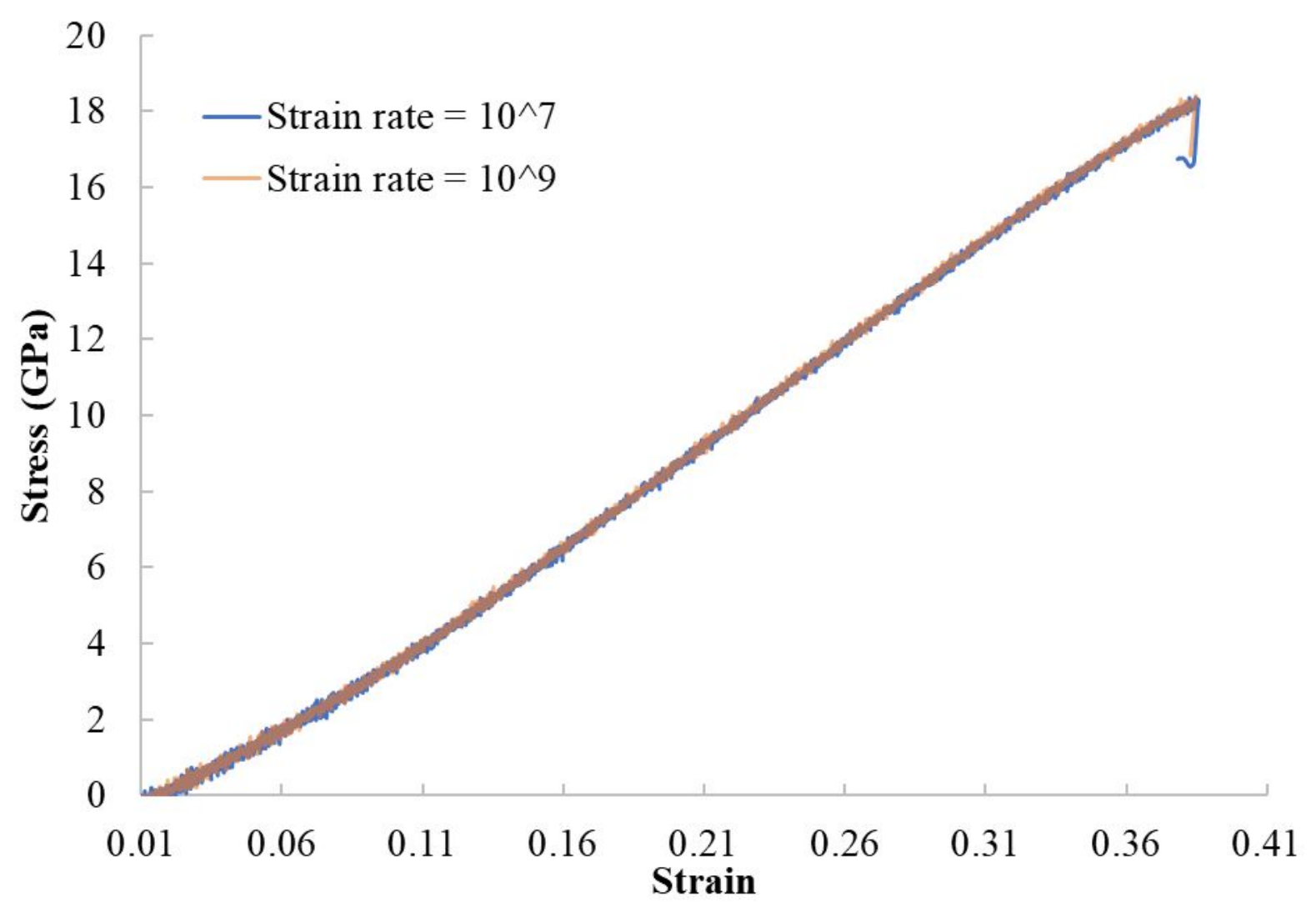

Figure S5. Stress-Strain curves for two tensile tests for a CCNT $(5,5,6,7,1,7)$ with two different strain rates of $10^{7} \mathrm{~s}^{-1}$ and $10^{9} \mathrm{~s}^{-1}$.

\section{Theoretical equations for large CCNTs}

After fitting the theoretical model to the results of MD simulation, for large CCNTs the corresponding coefficient of Equation (13) is defined as

$$
k=0.44 e^{0.67 \theta}-1.68 e^{-11.97 \theta}
$$

The correlation between $\sigma_{\mathrm{y}}$ and $\varepsilon_{\mathrm{y}}$ in the Pareto front solutions can be expressed as

$$
\sigma_{y}=7.44 \varepsilon_{y}^{-0.38}
$$

By solving Equation (2) at the yield point, the equation of yield point values dependent on geometrical parameters are derived as

$$
\varepsilon_{y}=\left(\frac{7449 \pi R^{2}}{250 d l \xi k}\right)^{0.72}
$$




$$
\sigma_{y}=\frac{d l \xi k}{4 \pi R^{2}}\left(\frac{7449 \pi R^{2}}{250 d l \xi k}\right)^{0.72}
$$

\section{Videos for molecular simulation of tensile tests}

Video S1. (12.7 MB, MP4 format) - Side- and top-view of molecular dynamics simulation of five small CCNTs with $\varepsilon_{\mathrm{y}}=0.23,0.48,0.96,1.46,2.95$ under tension.

Video S2. (13.9 MB, MP4 format) - Side- and top-view of molecular dynamics simulation of two CCNTs with similar coil diameter and different yield strain under tension. The grey lines show the displacement vectors of atoms during tensile test.

Video S3. (19.5 MB, MP4 format) - Side- and top-view of molecular dynamics simulation of five large CCNTs with $\varepsilon_{\mathrm{y}}=0.44,1.21,1.95,2.94,4.10$ under tension.

\section{References}

(1) Volodin, A.; Buntinx, D.; Ahlskog, M.; Fonseca, A.; Nagy, J. B.; Van Haesendonck, C. Coiled Carbon Nanotubes as Self-Sensing Mechanical Resonators. Nano Lett. 2004.

(2) Chen, X.; Zhang, S.; Dikin, D. A.; Ding, W.; Ruoff, R. S.; Pan, L.; Nakayama, Y. Mechanics of a Carbon Nanocoil. Nano Lett. 2003, 3 (9), 1299-1304.

(3) Hayashida, T.; Pan, L.; Nakayama, Y. Mechanical and Electrical Properties of Carbon Tubule Nanocoils. Phys. B Condens. Matter 2002, 323 (1-4), 352-353.

(4) Yonemura, T.; Suda, Y.; Tanoue, H.; Takikawa, H.; Ue, H.; Shimizu, K.; Umeda, Y. Torsion Fracture of Carbon Nanocoils. J. Appl. Phys. 2012, 112 (8), 84311.

(5) Shang, Y.; He, X.; Li, Y.; Zhang, L.; Li, Z.; Ji, C.; Shi, E.; Li, P.; Zhu, K.; Peng, Q.; Wang, C.; Zhang, X.; Wang, R.; Wei, J.; Wang, K.; Zhu, H.; Wu, D.; Cao, A. SuperStretchable Spring-Like Carbon Nanotube Ropes. Adv. Mater. 2012, 24 (21), 28962900.

(6) Deng, C.; Li, C.; Wang, P.; Wang, X.; Pan, L. Revealing the Linear Relationship between Electrical, Thermal, Mechanical and Structural Properties of Carbon Nanocoils. Phys. Chem. Chem. Phys. 2018, 20 (19), 13316-13321.

(7) Yonemura, T.; Suda, Y.; Shima, H.; Nakamura, Y. Real-Time Deformation of Carbon Nanocoils under Axial Loading. Carbon N. Y. 2014, 83, 183-187.

(8) Barber, J. R.; Boyles, J. S.; Ferri, A. A.; Bottomley, L. A. Empirical Correlation of the Morphology of Coiled Carbon Nanotubes with Their Response to Axial Compression. J. Nanotechnol. 2014, 2014.

(9) Ghaderi, S. H.; Hajiesmaili, E. Nonlinear Analysis of Coiled Carbon Nanotubes Using the Molecular Dynamics Finite Element Method. Mater. Sci. Eng. A 2013, 582, 225234. 
(10) Feng, C.; Liew, K. M.; He, P.; Wu, A. Predicting Mechanical Properties of Carbon Nanosprings Based on Molecular Mechanics Simulation. Compos. Struct. 2014, 114 (0), 41-50.

(11) Wu, J.; Nagao, S.; He, J.; Zhang, Z. Nanohinge-Induced Plasticity of Helical Carbon Nanotubes. Small 2013, 9 (21), 3561-3566.

(12) Shahini, E.; Karimi Taheri, K.; Karimi Taheri, A. An Investigation on Tensile Properties of Coiled Carbon Nanotubes Using Molecular Dynamics Simulation. Diam. Relat. Mater. 2017, 74, 154-163.

(13) Wu, J.; Zhao, H.; Liu, J.; Zhang, Z.; Ning, F.; Liu, Y. Nanotube-Chirality-Controlled Tensile Characteristics in Coiled Carbon Metastructures. Carbon N. Y. 2018, 133, 335-349.

(14) Sharifian, A.; Baghani, M.; Wu, J.; Odegard, G. M.; Baniassadi, M. Insight into Geometry-Controlled Mechanical Properties of Spiral Carbon-Based Nanostructures. J. Phys. Chem. C 2019, 123 (5), 3226-3238.

(15) Wang, J.; Kemper, T.; Liang, T.; Sinnott, S. B. Predicted Mechanical Properties of a Coiled Carbon Nanotube. Carbon N. Y. 2012, 50 (3), 968-976.

(16) Tamura, R.; Tsukada, M. Disclinations of Monolayer Graphite and Their Electronic States. Phys. Rev. B 1994.

(17) Suenaga, K.; Wakabayashi, H.; Koshino, M.; Sato, Y.; Urita, K.; Iijima, S. Imaging Active Topological Defects in Carbon Nanotubes. Nat. Nanotechnol. 2007.

(18) Chuang, C.; Fan, Y.-C.; Jin, B.-Y. Generalized Classification Scheme of Toroidal and Helical Carbon Nanotubes. J. Chem. Inf. Model. 2009, 49 (2), 361-368.

(19) Chuang, C.; Fan, Y.-C.; Jin, B.-Y. On the Structural Rules of Helically Coiled Carbon Nanotubes. J. Mol. Struct. 2012, 1008, 1-7.

(20) Lenosky, T.; Gonze, X.; Teter, M.; Elser, V. Energetics of Negatively Curved Graphitic Carbon. Nature 1992.

(21) Miettinen, K. Nonlinear Multiobjective Optimization; Springer Science \& Business Media, 2012.

(22) Coello, C. A.; Coello, G. B. L.; Van Veldhuizen, D. A. Evolutionary Algorithms for Solving Multi-Objective Problems; Springer, 2007.

(23) Dehuri, S.; Jagadev, A. K.; Panda, M. Multi-Objective Swarm Intelligence: Theoretical Advances and Applications; Springer, 2015.

(24) Wang, Y. M.; Bringa, E. M.; McNaney, J. M.; Victoria, M.; Caro, A.; Hodge, A. M.; Smith, R.; Torralva, B.; Remington, B. A.; Schuh, C. A.; Jamarkani, H.; Meyers, M. A. Deforming Nanocrystalline Nickel at Ultrahigh Strain Rates. Appl. Phys. Lett. 2006.

(25) Schioøtz, J.; Jacobsen, K. W. A Maximum in the Strength of Nanocrystalline Copper. Science (80-.) 2003. 
(26) Rajgarhia, R. K.; Spearot, D. E.; Saxena, A. Plastic Deformation of Nanocrystalline Copper-Antimony Alloys. J. Mater. Res. 2010. 